\title{
Home-made Compression Stockings and Shoes of a Cotton-Polyester Material in the Treatment of Primary Congenital Lymphedema
}

\author{
José Maria Pereira de Godoy • Lina M. O. Azoubel • \\ Maria de Fátima Guerreiro de Godoy
}

Received: 14 February 2010 /Accepted: 15 June 2010 /Published online: 30 September 2010

(C) Dr. K C Chaudhuri Foundation 2010

Sir,

The recommended treatment of lymphedema is the association of therapies such as manual and mechanical lymph drainage, compression therapy (hosiery and bandaging), exercising, myolymphokinetic activities and hygienic precautions $[1-3]$. In primary congenital lymphedema, the forms of treatment are the same but the treatment must be adapted for children with respect to their social reality. The objective of the current study is to report on the treatment of congenital lymphedema utilizing stockings and shoes made of a cotton-polyester material.

Five children with primary congenital lymphedema of the lower extremities who used compression stockings made of a cotton-polyester material were evaluated in the period from 2002 to 2009 in the Godoy Clinic. This cottonpolyester material, called gorgurão in Brazil, has low

\footnotetext{
J. M. P. de Godoy

Department of Cardiology and Cardiovascular Surgery,

Medical School of São Jose do Rio Preto-FAMERP-Brazil and $\mathrm{CNPq}$ (National Council for Research and Development), São José do Rio Preto, Brazil

L. M. O. Azoubel

Godoy Clinic,

São José do Rio Preto, Brazil

M. d. F. G. de Godoy

Godoy Clinic and Research CAPES (Coordination

of Improvement of Personal of Superior Level),

São José do Rio Preto, Brazil

e-mail: godoyjmp@riopreto.com.br

J. M. P. de Godoy

Rua Floriano Peixoto, 2950,

São José do Rio Preto, SP, Brazil 15010-020
}

elasticity $(<50)$ across the material and is elastic along the material and thus allows low-stretch compression. The home-made stockings used in this study constantly require readjustment because of reductions in the size of the limb. Shoes are made of the same material with a rubber sole and can be made attractive to children using different colors. The diagnosis of lymphedema was clinical and by two perimetric measurements $(3$ and $6 \mathrm{~cm}$ ) of the dorsum of the feet. The size of the contralateral limb was used as a comparison. The Tukey-Kramer Multiple Comparisons Test was employed for statistical analysis with an alpha error of $5 \%$ ( $p$-value $<0.05)$ considered acceptable. The consent form was signed by familiar responsible. The study was approved by the ethics committee in Medicine School of São Jose do Rio Preto-FAMERP-Brazil (n03375-2009)

The reduction between the initial and final measurements seen with treatment was significant (two-tailed $t$-test: $p$-value $<0.0001)$.After treatment the sizes of the two feet were within the normal range (two-tailed $t$-test: $p$-value $<0.3)$.

The longer adequate compression is used during the day the better the result. Use without adjustments is of little value as improvement will be limited or inexistent. Support of the family and of the people who live daily with young patients is important.

It is possible to normalize the edema just with the use of compression stockings, but as edema is an incurable disease treatment is life long. The association of other forms of treatment, such as manual and mechanical lymph drainage and cervical stimulation, provides a synergic effect. Thus an association of techniques is recommended to control the edema faster. The independence that the family achieves with this alternative changes the history of the therapy of lymphedema as the family is able to treat their own child. 


\section{References}

1. de Godoy JM, de Godoy MFG. Development and evaluation of a new apparatus for lymph drainage: preliminary results. Lymphology. 2004;37(2):62-4.
2. Kerchner K, Fleischer A, Yosipovitch G. Lower extremity lymphedema update: pathophysiology, diagnosis, and treatment guidelines. J Am Acad Dermatol. 2008;59(2):324-31.

3. de Godoy MFG, de Godoy JMP, Braile DM. Pilot study with Myolymphokinetic activities in the treatment of lymphedema after breast cancer. Indian J Physiother Occup Ther. 2008;2(3):17-9. 